\title{
Pais e médicos precisam conhecer e recomendar as vacinas contra HPV
}

As vacinas contra os tipos mais agressivos de Papilomavírus Humano(HPV)são muito bem-vindas, pois vão reduzira incidência do câncer cervical uterino, diminuirão o estresse provocado por resultados anormais nos exames citológicos ou pelo diagnóstico de uma doençainfecciosa sexualmente transmitida e pouparão gastos referentes aos cuidados com a saúde'. Mas para atingir tais benefícios, é indispensável que a vacina seja realmente aceita pelos grupos de pessoas nos quais ela será indicada, isto é, nos jovens ou crianças préadolescentes. Esta aceitação envolve aspectos muito peculiares, sendo indispensável avaliar a percepção do problema pelos diversos atores envolvidos como os usuários, suas famílias, os profissionais daárea da saúde (com suas respectivas instituições) e a sociedade em geral ${ }^{2}$.

Nas decisões sobre o emprego da vacina deve-se encarar a progressiva redução da idade com que rapazes e moças do mundo ocidental iniciam a atividade sexual. Um estudo de 2005, nos Estados Unidos, constatou que $5,7 \%$ das meninas e 7,9\% dos meninos já tinham se iniciado nas práticas sexuais. Desta forma, a vacinação deve ser indicada para pré-adolescentes ou jovens no início da adolescência para obter o maior benefício possível da prevenção ${ }^{3}$.

Recentes estudos de campo procuram esclarecer o grau de conhecimento das mulheres sobre o HPV e as principais variáveis que têm influência na citada percepção quanto ao emprego da vacina. Muitos destes estudos procedem da Europa e América do Norte, pois não existem trabalhos brasileiros correspondentes, encontrando-se apenas os realizados com mulheres já portadoras de HPV.
Como o benefício da vacina só ocorre para pessoas que ainda não contraíram a infecção pelo HIV, os alvos principais das campanhas de vacinação deverão ser jovens na pré-adolescência e na adolescência precoce. Pesquisas feitas com a vacina contra hepatite $B$ nestes grupos etários mostram que os indivíduos confiam nos pais para questões de vacina ${ }^{4}$.

Os profissionais da área da saúde têm papel importante no sentido de influenciar os pais e os usuários para a aceitação da vacina contra HPV. É preciso que eles desenvolvam conhecimentos e habilidades para tal tarefa. Além disso, nos Estados Unidos já se demonstrou que o grau de endosso destes profissionais às imunizações, de modo geral, depende muito da recomendação das associações de classe.

Paulo Aligieri

\section{Referências}

1. Goldie SJ, Kohli M, Grima D, Weinstein MC, Wright TC, Bosch FX et al. Projected clinical benefits and cost-effectiveness of a human papillomavirus 16/18 vaccine. J Natl Cancer Inst. 2004;96(8):604- I5.

2. Sturm LA, Mays RM, Zimet GD. Parental beliefs and decision making about child and adolescent immunization: from polio to sexually transmitted infections. J Dev Behav Pediatr. 2005;26(6):441-52.

3. Rosenthal SL. Protecting their adolescents from harm: parental views on STI vaccination. J Adolesc Health. 2005;37(I):177- 8.

4. Rosenthal SL, Kottenhahn RK, Biro FM, Succop PA. Hepatitis B vaccine acceptance among adolescents and their parents. J Adolesc Health. 1995; $17(2): 248-54$. 